\title{
Mosquito Control.
}

\section{Opening of a New Institute at Hayling Island.}

$A$ NEW phase in the control of the mosquito problem was reached last week when members of the Section of Zoology of the British Association attended the opening of the British Mosquito Control Institute, which has been founded and equipped by Mr. J. F. Marshall in his own grounds at Hayling Island, Hants.

The new building (Fig. I) occupies two stories and includes a demonstration museum, a laboratory, drawing and record offices, photographic rooms, a library, and a mechanical workshop. There are also a number of smaller rooms designed for research students. It already contains a wealth of material for mosquito study not available elsewhere, and historical records of how the mosquito has been successfully combated on the island.

The formal opening, which took place on Monday, August 3I, was presided over by Sir Richard Gregory, chairman of the Council of the new Institute. As a result of the preventive work undertaken, which has consist ed largely of draining the inter-tidal areas, $\mathrm{Hay}$ ling Island, which formerly was infested .with "saltmarsh" mosquitoes, has now been practically cleared. In introducing the subject, the chairman pointed out that in many parts of the world the question was whether the
FIG. r.-The British Mosquito Control Institute.

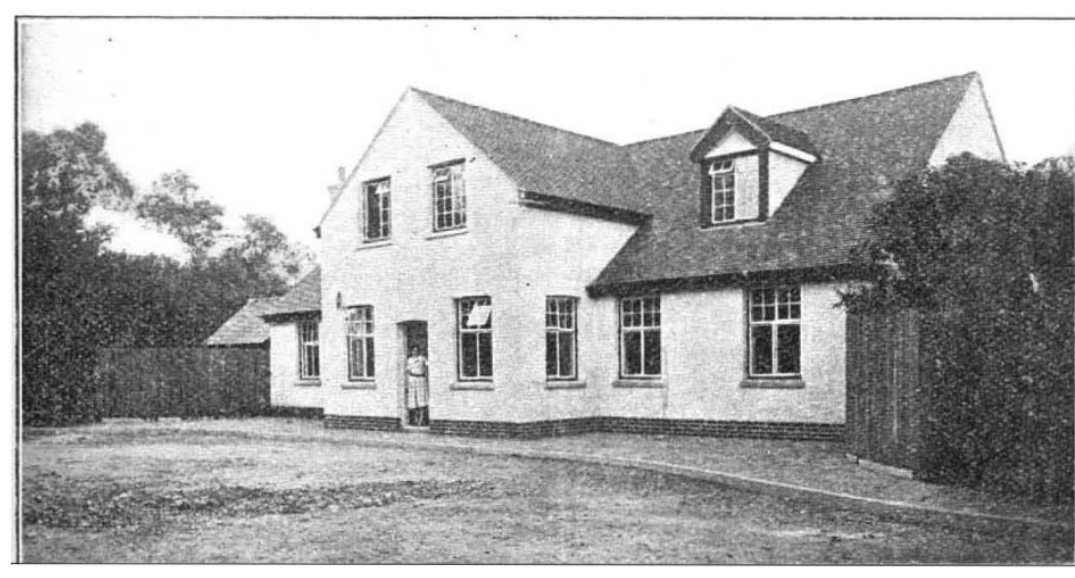

mosquitoes but also all those dangerous and unpleasant pests that prey on man and on his crops and herds. It is ridiculous that while man dominates the earth, the sea and the air, he should continue to be the prey of bacilli and even die from such contemptible things as colds in the head and mosquito bites. Improved medical and sanitary science and administration have, in the last eighty years, increased the average length of human life in Great Britain by about fifty per cent., yet men still die of many diseases which will one day be conquered. Sir Ronald Ross pleaded for the expenditure of a million pounds a year on medical research so as to accelerate the conquest of disease. Such a sum would be trivial compared with the money now spent on tobacco, alcohol, and entertainment, without taking into account what is spent on education, armaments, and the "dole." While the work of the new Institute is to be general rather than medical, it will unquestionably keep the sanitary applications of mosquito control within range of its vision. The knowledge gained in the Institute will facilitate mosquito control in every region of the earth, and it is certain that the day will come when the fertile tracts now ravaged by king Malaria a n d kin Mosquito will mosquito or man should survive. It was, he said, one of the glories of British science that much of its best work had been done by men who were not professional workers but had studied Nature simply because of the desire to gain knowledge, and without any ulterior motive. Mr. Marshall had been responsible for work of that kind, and the result of it was the building that was about to be opened, the British Mosquito Control Institute.

Sir Ronald Ross, in opening the Institute, described his own experiences at Hayling Island some three years ago. He had, he admitted, been sceptical as to the accusations made against Ochlerotatus detritus, the salt-water mosquito. Mr. Marshall, however, had convinced him by taking him to a part of his garden and inviting him to observe the insects flying about in broad daylight. In the course of his observations, Mr. Marshall had proved his point by directing his attention to the fact that three of the insects were simultaneously extracting blood from the back of his neck. Sir Ronald Ross pointed out that when he began work on the mosquito there was not a book or a good article dealing with the mosquitoes in India. Much is now known, but, in addition to knowledge, energy is necessary for acting upon it. What has been done in the Panama, at Ismailia, and in the Federated Malay States is only a beginning. $\mathrm{He}$ insisted on the importance of controlling not only the be laid open to civilisation. This happy result will however, only be attained by more thought, by more research, and by a firmer determination to make the most of the beautiful world in which we live.

A vote of thanks to Mr. Marshall was proposed by Mr. C. Tate Regan and seconded by Col. James, of the Medical Department of the Ministry of Health. The Ministry, he said, greatly appreciates the good work done by Mr. Marshall. Col. James emphasised the importance of voluntary assistance given to the Government, and said that it is on this that the success of public health administration largely depends. He promised on behalf of the Ministry that it would watch the working of the Institute with great and, he hoped, helpful interest.

The ceremony concluded with a few words of thanks from Mr. Marshall, and it was announced that the composition of the Council of the Institute is as follows :-Major E. E. Austen, Dr. Andrew Balfour, Mr. F. Balfour-Browne, Sir James Crichton-Browne, Dr. H. Eltringham, Sir Richard Gregory, Col. S. P. James, Dr. G. A. K. Marshall, Prof. H. Maxwell Lefroy, Prof. E. B. Poulton, Sir Ronald Ross, Dr. Hugh Scott, Sir Arthur E. Shipley, Prof. Sir William Simpson, and Dr. C. M. Wenyon. The Trustees are Sir Richard Gregory and Mr. L. W. North Hickley, and the honorary firector, Mr. J. F. Marshall. 